\title{
“AVALIAÇÃO ESCOLAR NA VISÃO DE ALUNOS E PROFESSORES DE PSICOLOGIA: O COTIDIANO DA SALA DE AULA"
}

\author{
MARILICIA WITZLER A.R. PALMIERI ${ }^{1}$ \\ MARIA CRISTIINA C. VALLE
}

\begin{abstract}
PALMIERI, M. W. A. R. e VALLE, M. C. O. Avaliação escolar na visão de alunos e professores de psicologia: 0 cotidiano da sala de aula. Semina: Ci. Soc./Hum., Londrina, v.16. n. 2., Ed. Especial, p. 20-26, out. 1995.

RESUMO: O presente estudo teve por objetivo o posicionamento de docentes e discentes acerca de uma questão polêmica - a avaliação escolar - e constatar através dos dados das duas populações investigadas, a coerência do discurso com a prática avaliativa. Para obtenção dos dados entrevistou-se 03 docentes do Departamento de Psicologia Social e Institucional da Universidade Estadual de Londrina e 05 discentes que cursavam cada disciplina investigada, totalizando 15 alunos. Coletou-se os dados mediante instrumentos previamente elaborados. Junto aos professores utilizou-se um roteiro de entrevistas e com os alunos optou-se pela utilização de um questionário. Os resultados obtidos revelam posicionamentos diferentes por parte dos professores e com relação aos alunos, embora façam críticas à prova escrita individual, por esta exigir reprodução de conteúdo e memorização, consideram-na como o único meio de avaliar o processo ensino-aprendizagem.
\end{abstract}

PALAVRAS-CHAVE: Avaliação, instrumentos de avaliação, avaliação educacional e escolar, Processo ensinoaprendizagem, rendimento escolar.

\section{O PROBLEMA:}

A centralização do presente trabalho no estudo sobre "avaliação escolar" tem origem na nossa própria atividade profissional. Enquanto docentes do curso de Psicologia da UEL, constatamos já há algum tempo um descompasso no posicionamento de docentes e discentes quanto à esta questão.

O curso de Psicologia da UEL encontra-se subdividido administrativamente em 03 departamentos: Psicologia Geral e Análise do Comportamento; Fundamentos de Psicologia e Psicanálise; Psicologia Social e Institucional.

Mesmo com a divisão administrativa, na periodização curricular, as disciplinas se cruzam, possibilitando identificar junto aos alunos, a queixa direcionada para a "avaliação escolar" no curso de Psicologia como um todo.

As dificuldades freqüentemente apontadas, rumam para a questão das divergências nas disciplinas quanto às formas de avaliação, critérios de correção e objetivos dos instrumentos avaliativos.

Por ser um tema polêmico e por ocasionar, na maioria das vezes, julgamento, surgem ocasionalmente conflitos diversos entre avaliador e avaliados.

Visualiza-se que tanto docentes quanto discentes conseguem perceber que alguma coisa não vai bem, porém, os objetivos e formas de avaliação parecem ser "intocáveis", mantendo-se os mesmos ao longo dos tempos.

Assim sendo, pretende-se investigar neste estudo a relação entre as formas de avaliação e os objetivos pretendidos em disciplinas teóricas do curso de Psicologia da Universidade Estadual de Londrina.

A proposição do presente estudo é a de, através da "metodologia da problematização", iniciar um processo que vai desde a constatação da realidade, passando por análises e reflexões sobre a questão até a seleção de estratégias que propiciem uma reflexão conjunta e conseqüentemente conscientizadora.

Para iniciar tal processo, optou-se pela delimitação da população a ser investigada, para posterior ampliação da mesma, a nivel de análise e reflexão.

Selecionou-se, portanto, o Departamento de Psicologia Social e Institucional, dentre os três, por ser este o nosso Departamento de origem, facilitando assim, o contato com os docentes e discentes.

\section{PONTOS-CHAVE DO PROBLEMA:}

Com a intenção de explorar e delimitar o PROBLEMA a ser investigado, faz-se necessário num primeiro momento, explicitar as causas mais imediatas com o intuito de aprofundar estudos em torno da problemática da avaliação escolar.

Coloca-se assim, a questão básica: de onde surgiu esse problema?

No plano objetivo, aparentemente, as causas imediatas assim se explicitam: a) a dissociação entre o discurso proferido e a prática pedagógica utilizada; b) a utilização de critérios classificatórios para avaliar o processo ensino-aprendizagem; c) ausência de sintonia entre as formas de avaliação e objetivos pretendidos nas disciplinas teóricas; d) a insatisfação dos alunos quanto

1. Docentes do Departamento de Psicologia Social e Institucional da Universidade Estadual de Londrina, Londrina, Paraná, Brasil, Caixa Postal 6001, CEP 86051-970.

- Mestrandas do Curso de Mestrado em Educação/UEL

Semina: Ci. Soc./Hum. v.16., n. 2, Ed. Especial, p. 20-26. out. 1995 
a adoção de critérios subjetivos de correção por parte dos professores.

Explicitadas as causas mais imediatas do problema a ser investigado, surge a necessidade de se questionar e refletir sobre a avaliação escolar num plano mais amplo. Isto porque há determinantes maiores, que de uma forma ou de outra, estão envolvidos no processo avaliativo como um todo e, não deseja-se aqui, apenas constatar uma necessidade, mas conhecê-la em sua profundidade. Para tanto, há que se considerar as mediações ideológicas presentes no próprio processo ensinoaprendizagem, incluindo-se aí, a questão da avaliação.

Assim, a prática avaliativa adotada atualmente, pode estar sedimentada numa relação hierárquica e autoritária no contexto do processo ensinoaprendizagem, assegurando a reprodução de práticas sociais existentes. Ou seja, reproduz-se na prática avaliativa, uma concepção liberal de educação atrelada a uma visão de conhecimento positivista pautada na observação e registro de dados.

Nesta direção, observa-se que o aparelho escolar não está isolado do contexto sócio-político, pelo contrário, está inserido neste, refletindo as contradições da sociedade por onde perpassa a própria ideologia. Desta forma, a relação entre o Professor, o Aluno e o Objeto de Conhecimento, vem sendo trabalhada numa perspectiva reprodutivista, pela própria estrutura da sociedade, dividida em classes sociais antagônicas, que reproduz as relações sociais e, conseqüentemente, a manutenção de suas formas de produção.

À serviço da conservação da sociedade, a prática da avaliação pode estar engajada na manutenção do "status quo" e reproduzindo o esperado, ou seja, se utilizando de um sistema classificatório, onde o "sucesso" ou "insucesso" do processo ensino-aprendizagem sejam direcionados para a esfera individual.

Portanto, o "sucesso" ou "insucesso" do processo ensino-aprendizagem cabe ao aluno e, a prática da avaliação pode estar contribuindo para selecionar os aptos e não aptos para atuarem posteriormente na sociedade.

Assim, a avaliação escolar pode estar também comprometida em encontrar formas de adequar os indivíduos aos padrões "normais", ditados pela sociedade mais ampla.

Cabe então, sondar como o professor e o aluno percebem o processo avaliativo, a partir da prática vivenciada.

\section{TEORIZAÇÃO:}

\subsection{DA AVALIAÇÃO INSTITUCIONAL À AVALIAÇÃO ESCOLAR: NECESSIDADE PRIORITÁRIA NO ENSINO}

A Educação no Brasil é alvo hoje de muitas análises e reflexões, sendo viável considerar a ocorrência de muitos avanços no que concerne à alteração, embora primária, da visão do Educador com relação à prática educacional.
Os professores vêm assumindo um compromisso de procurar alternativas para a construção de uma escola inovada, principalmente no que diz respelto às práticas pedagógicas. Porém, alguns indicativos e resquícios da educação "tradiciona!", mantêm-se como que impregnados na postura do professor.

A imagem da autoridade e poder norteia o trabalho do professor na definição de objetivos, estratégias de ensino e avaliação escolar, conservando e preservando uma sociedade autoritária.

LUCKESI (1984) referiu-se assim em relação às práticas pedagógicas: "Estas, não estão sendo efetuadas gratuitamente, mas sim a serviço de uma pedagogia que condiz como uma concepção de educação, que por sua vez, é perfeitamente plausivel com uma concepção teórica da sociedade" (p.23).

Provavelmente, esses resquícios de educação tradicional perdurem, mantendo um modelo teórico de sociedade e educação, sem a consciência e intenção dos educadores. A falta de conhecimento e aprofundamento nas questões filosóficas da educação pode gerar ações que aparentemente se mostrem ingênuas e neutras, fazendo parte de um processo habitual e familiar com técnicas e definiçōes educacionais.

Durante muitos anos primou-se por considerar o ato de planejar como neutro $\Theta$ automático, resumindose ao simples cumprimento de exigências administrativas, e na prática educacional, voltado para - preenchimento de formulários para íniciar o anol semestre letivo.

O planejamento ou projeto educacional envolve assim uma dimensão política, onde nenhuma proposta educacional é meramente técnica. Segundo FERRET! (1987), a dimensão política "é uma das formas de expressão de um projeto político mais amplo, que dele tenham ou não consciência plena ou parcial seus executores" (p.114).

Para LUCKESI (1984), o planejamento entendido como ato político, deve ser dinâmico, sujeito a constante tomada de decisão. Não necessariamente exige registro em documento escrito. Só como memória viva ele já faz sentido.

LUCKESI (1986) afirma também que existem dois grupos de pedagogias que exigem práticas diferentes de avaliação educacional e escolar. No primeiro modelo liberal conservador, obrigatoriamente, a avaliação será autoritária. Ao contrário, no modelo transformador, deverá se ater à autonomia do educando, com a participação democrática de todos.

Segundo RAMOS (Apud CAMPANER et al, 1993), a avaliação deve ser feita em função de conteúdos que possam levar ao estabelecimento de consciência crítica, ficando para o professor, não o julgamento dogmático, mas sim o processo de democratização do saber universal.

A análise social e educacional descrita por LUCKESI (1986) é perfeitamente relevante e indispensável em um processo de conscientização de educadores, acerca do procedimento avaliativo.

LUCKESI considera ainda, que a avaliação escolar sugere dois tipos de prática avaliativa, a classificatórla e a diagnóstica. Ressalta também que, na atual prática escolar, predomina a avaliação classificatória em 
detrimento da segunda.

$\mathrm{Na}$ avaliação classificatória prevalece o julgamento do professor, sendo que cabe aqui, à avaliação, a função somente de classificar um objeto ou um ser humano histórico, em um padrão determinado.

Neste tipo de avaliação, após trabalhada a unidade de estudo, é feita a verificação do aprendido, atribuindose pontos ou notas. Estes simbolos são registrados e, definitivamente, o educando permanecerá nesta situação.

Este julgamento se dá a um ser humano, que é histórico, mas que torna-se estigmatizado a partir dos símbolos a ele atribuídos.

Por outro lado, na avaliação diagnóstica, o ato de avaliar deve servir como uma parada para pensar a prática e retornar a ela. Sendo a aprendizagem um processo dinâmico, cabe também um sistema de avaliação dinâmico, possibilitando constantemente a retroalimentação no processo ensino-aprendizagem.

Quando se está avaliando uma ação, obrigatoriamente deve ocorrer a tomada de decisão quanto à ação, e não o julgamento e estratificação da mesma.

Diante do modelo social predominante e da atual prática avaliativa, na maioria das vezes, classificatória, surgiu nossa preocupação com o tema mais pormenorizada de nossa realidade prática, contribuirmos na criação de oportunidades para iniciar um processo de conscientização, tanto de educadores como de educandos.

Portanto, no presente estudo objetivou-se:

- verificar o posicionamento de docentes e discentes acerca da avaliação escolar;

- constatar a coerência do discurso com a prática avaliativa junto a docentes e discentes.

\section{2 - A FORMA DE INVESTIGAÇÃO}

Para a realização deste trabalho, selecionou-se o Departamento de Psicologia Social e Institucional da UEL, subdividido em três áreas de conhecimento, a saber: Psicologia Escolar; Psicologia Organizacional e Psicologia Social.

Estabeleceu-se dois universos de investigação: Docentes e Discentes.

\section{3 - caracterizaÇão da população INVESTIGADA}

Para a escolha dos docentes, foi efetuado um levantamento junto às disciplinas teóricas que compõem cada uma das áreas acima mencionadas. Procedeu-se a um sorteio dentre as disciplinas teóricas, onde selecionou-se um docente responsável em ministrar a mesma. Assim, os professores consultados são em número de três, ou seja: um de cada área específica.

Com relação à seleção dos alunos, procedeu-se da seguinte forma: através da lista de freqüência das 3 disciplinas sorteadas, efetuou-se um sorteio de 5 alunos por disciplina, totalizando 15 alunos investigados.

\section{4 - OS INSTRUMENTOS UTILIZADOS}

a) Com relação aos professores:
A opção por um roteiro de entrevista fez-se em função de que, algumas informações solicitadas, envolviam questões que proporcionavam certa reflexão e análise do professor em relação à sua prática na avaliação escolar, bem como forneciam dados mais ricos e abrangentes sobre o problema em questão.

$\mathrm{Na}$ estruturação do roteiro foram considerados os seguintes aspectos: principais preocupações quanto à avaliação na UEL; a relação entre avaliação e objetivos das disciplinas; em formas de avaliação utilizadas; critérios para seleção e correção das avaliações; retroalimentação das dificuldades detectadas nas avaliações; reações dos alunos quanto à avaliação; comentários, críticas e sugestōes.

As entrevistas foram realizadas individualmente por 2 entrevistadores, tendo a duração média de 30 minutos, onde solicitou-se aos professores a lista de freqüência para o sorteio dos alunos.

\section{b) Com relação aos alunos:}

Para a coleta de dados optou-se pela aplicação de um questionário por duas razões: $1^{\text {z }}$ - a amostra constituir-se de um número significativamente elevado (15), e $2^{\text {a }}$ - evitar constrangimento por parte dos alunos em expressar opiniões sobre os processos de avaliação de determinadas disciplinas.

A elaboração do questionário priorizou: formas de avaliação na disciplina; conhecimento dos objetivos e critérios de correção; relação entre objetivos e avaliação; coerência entre proposta de ensino-aprendizagem e critérios de avaliação; principais preocupações quanto à avaliação no curso de Psicologia; reações frente às situações de avaliação; comentários, criticas e sugestões.

Contatuou-se os alunos em sala de aula, quando eram ministradas outras disciplinas, que não as selecionadas no presente trabalho.

\section{5 - A APRESENTAÇÃO DOS DADOS}

A apresentação dos resultados obtidos na investigação será dirigida em torno das opiniōes dos professores, e em seguida, com relação aos alunos. Os dados serão apresentados de forma agrupada, contemplando análise e discussão dos aspectos investigados junto aos docentes e alunos, através dos instrumentos utilizados.

\subsection{1 - QUANTO AOS PROFESSORES}

- Principais preocupações quanto à avaliação dos alunos na UEL:

Com relação a este aspecto obteve-se duas opiniões divergentes. Na primeira, o posicionamento procede a criticas quanto aos critérios classificatorios e autoritários exigidos formalmente pela própria Instituição. Assim, ressaltam que esta exigência da Instituição dificulta modificações na prática da avaliaçāo escolar. ficando a responsabilidade de atribuir "nota" e medir desempenho nas mãos do professor.

Em contrapartida, na segunda, as preocupações 
se direcionam tanto para a natureza da avaliação, quanto na relação entre o tipo de avaliação e o conteúdo a ser avaliado. Este posicionamento não critica as exigências formais como o primeiro, pelo contrário, reafirma a importância no próprio instrumento de avaliação, pois coloca que este "deverá ser capaz de refletir o aprendizado".

Frente a tais posicionamentos, percebe-se a reafirmação da prática da avaliação escolar sob uma perspectiva conservadora. Isto porque, apesar de um grupo de professores posicionar-se teoricamente identificando os critérios autoritários e classificatórios da avaliação, na prática mantém posturas incompatíveis com um discurso justificado pelas exigências formais da Instituição. Em suma, deixam de inovar a prática pedagógica, mesmo tendo consciência da necessidade de mudança desta em função de exigências avaliativas tradicionais.

\section{- A prática da avaliação escolar:}

Os professores entrevistados consideraram que há uma estreita relação entre avaliação e objetivos da disciplina. Porém, observou-se que esta relação se justifica em termos do resultado da transmissão de conteúdos e não em termos do processo ensinoaprendizagem em si, ou seja, destacam a relação "ementa da disciplina e avaliação".

Percebeu-se também, nos relatos dos professores, que a avaliação de conteúdo possui uma característica quantitativa (cumprimento da ementa). Já o aspecto qualitativo ficaria relegado somente a atitudes éticas e habilidades profissionais (aspecto comportamental).

Quanto às formas de avaliação, as respostas obtidas demonstraram grande diversidade destas (seminários, pesquisa de campo, estudo de caso, entre outros), porém a prova escrita individual é unânime como opção dos entrevistados e, ainda considerada como a forma mais valorizada de avaliação formal (de conteúdo).

As respostas dos entrevistados expressam que os critérios de escolha das formas de avaliação se dão de diferentes maneiras. Assim, os relatos dos docentes entrevistados revelam diferentes elementos para escolherem as formas de avaliação em suas disciplinas.

Por um lado, apontaram a "especificidade do conteúdo", onde um conteúdo essencialmente teórico requer necessariamente uma avaliação escrita individual, avaliando o domínio de conceito, básicos pelo aluno. Por outro lado, destacam as condições do ensino, como: - número de alunos, recursos disponíveis, discussão prévia com os alunos quanto às formas de avaliação, entre outros. Esta última evidencia a participação do aluno no processo de escolha, porém não deixa claro o processo de participação.

Neste sentido, constata-se no relato da maioria dos professores entrevistados a tendência mais acentuada de verificação da aprendizagem através de testes formais, reforçando a manutenção da avaliação do tipo classificatória.

Conforme LUCKESI (1986), o que prevalece neste tipo de avaliação é o julgamento do professor, onde este, ao final de uma Unidade de Ensino, classifica o educando em termos de notas registradas, permanecendo este ŕa situação em que se encontrava anteriormente.

Isto é observado também no relato de um dos professores quando questionado se deixa claro para os alunos os critérios de correção das avaliações. Este afirmou não esclarecer os alunos sobre os critérios, argumentando que quando da correção, considera o conteúdo e a sua adequação.

Eis uma demonstração da subjetividade do professor na correção das avaliações, pois este acaba procedendo a julgamentos carregados de conceitos, valores e idéias pessoais.

Com relação ao processo de retroalimentação, observou-se que apesar dos professores relatarem que - adotam em sua disciplina, as estratégias utilizadas demonstram que não consideram como essenciais no processo ensino-aprendizagem, lançando mão de ações que não caracterizam um processo retroalimentador.

As opiniões dos professores quanto as reações mais frequentes dos alunos em situações de avaliação, apontam para a dificuldade dos alunos em compreender claramente os objetivos da avaliação, tais como: 1) consideram científicas as respostas baseadas no senso comum e 2) consideram a avaliação como disputa/ competição.

Por outro lado surgiram colocações referentes ao fato de que "o aluno não gosta de ser avaliado", ou então "não gostaram da prova, mas não reclama das outras formas de avaliação".

Supõe-se que estes dados revelem que os próprios professores consideram a avaliação "somente como prova escrita individual". Fica claro que na reação dos alunos não existe uma reclamação do sistema de avaliação adotado pelos professores, mas sim especificamente, desse tipo de avaliação (prova escrita individual).

Outras respostas relacionadas às reações dos alunos em situações de avaliação mostram que o tipo de avaliação adotado determina a "imagem" que o aluno tem do professor. Como por exemplo, consideram "o professor exigente ou não", "chegando até a ficar surpresos quando vão bem na prova", "contestam nota".

Cabe salientar que possivelmente a surpresa dos alunos está relacionada com a ausência de clareza dos critérios de correção e da própria estruturação das questões do instrumento de avaliação.

Quanto se proporcionou aos professores a oportunidade de livre expressão, obteve-se posicionamentos diversificados.

No primeiro, constata-se uma definição quanto à questão da avaliação, no sentido de que a mesma deve ser classificatória, ressaltando a importância do conteúdo sob a responsabilidade total do professor. Revela também a necessidade de uma discussão institucional, visando a garantia desse tipo de avaliação em todas as disciplinas dos cursos da UEL.

Outro posicionamento demonstra a preocupação do professor com a avaliação, sugerindo, inclusive, que a comunidade universitária se mobilize para discutir essa questão. Considera ainda que o aspecto quantitativo (nota) não deve ser eliminado do processo de avaliação, mas ressalta como essencial no processo avaliativo a formação do profissional e, conseqüentemente, do cidadão.

Uma crítica ao atual sistema avaliativo é apontada 
por um dos professores entrevistados, pois considera que este constitui-se em "obstáculo" ao crescimento, sendo que deveria se constituir em auxilio para a resolução de problemas.

Estes posicionamentos demonstram a diversificação das opiniões expressadas pelos professores entrevistados, pois mesmo existindo e fazendo uso de procedimentos pré-estabelecidos socialmente, percebeu-se que há questionamentos $e$ reflexōes em torno da avaliação educacional e escolar.

\subsection{2 - QUANTO AOS ALUNOS}

Para a coleta de dados junto aos alunos, utilizouse de um questionário, onde era especificada a disciplina que deveria nortear as duas respostas. Entretanto, de posse dos questionários, decidiu-se por apresentar e analisar os dados dos alunos, conjuntamente não especificando a disciplina correspondente. Justifica-se tal procedimento, objetivando uma análise mais pertinente do processo avaliativo, evitando assim, a avaliaçāo em torno de disciplinas específicas.

Desta forma, apresentar-se-á dados de um total de 15 alunos investigados, com a mesma disposição utilizada anteriormente quando da descrição dos dados dos professores.

\section{OPINIÃO dOS ALUNOS QUANTO À PRÁTICA AVALIATIVA:}

As formas de avaliação apontadas pelos alunos foram: prova escrita individual, trabalho escrito, análise de filmes, entre outras.

Observou-se que a maioria dos alunos apontaram a prova escrita individual como forma de avaliação utilizada nas disciplinas, inclusive, tecendo comentários relativos à exigência de memorização, ausência de análise crítica e não valorização do entendimento do conteúdo pelo aluno, nestas provas.

A percepção dos alunos quanto a relação entre objetivos da disciplina e avaliações, apresentou-se dividida, onde um grupo aponta conformidade com uma prática avaliativa tradicional, considerando assim, a avaliação como mediação de conhecimentos assimilados, através de instrumentos verificativos. Por outro lado, um segundo grupo de alunos demonstra uma consciência crítica, quando denunciam a ausência de coerência entre objetivos propostos numa dimensão transformadora e uma prática avaliativa conservadora.

Neste sentido destaca-se os seguintes argumentos usados pelos alunos que evidencia esta questão: "a avaliação visa a reprodução do conteúdo e não uma reflexão crítica dos conhecimentos como proposta nos objetivos"; "o conhecimento é posto em segundo plano e o objetivo passa a ser a nota"; "o professor orienta os objetivos da disciplina para si mesmo e os alunos não os atingem por falta de embasamento teórico".

O mesmo fato ocorreu quando investigou-se a coerência entre a proposta de ensino-aprendizagem e os critérios para correção das avaliações.

Devido a significância dos argumentos utilizados pelos alunos quanto a esta questão destacam-se dois, tal como apresentados:
- ausência de coerência entre uma proposta "crítica", "de análise", de "conscientização" e de "transformação social", com o tipo de instrumento avaliativo utilizado que requer "reprodução de conteúdo" e "onde o aluno é mero receptor passivo".

- apesar de perceber coerência, o problema maior é o da "relação de superioridade do professor para com - aluno", considerando, inclusive, que "a compreensão do conteúdo é inatingivel para os alunos".

Percebe-se, com relação a este aspecto a preocupação dos alunos quanto à coerência entre o discurso crítico e a prática avaliativa, onde demonstrase que, apesar do professor defender uma proposta transformadora, parece manter a avaliação à parte desta, ou seja, a avaliação é mantida numa prática conservadora.

Apontam ainda, a relação de poder estabelecida com a avaliação, onde o professor coloca-se em uma posição de controle, já que é o "detentora do poder " $e$ do "conhecimento" nesta situação. Assim, a avaliação antes de assumir a função de retroalimentação é tida como uma sentença final que mede, em si, todo o aprendizado.

Os alunos expressam ainda como se sentem frente às situações de avaliação. Destacam-se argumentos em torno do "estado emocional", no momento das avaliações, quando estas caracterizam-se por situações extremamente estressantes, que levam ao esquecimento do conteúdo memorizado, prejudicando o rendimento nas "provas".

O "clima" criado pelo professor antes da prova, é de tensão, gerando insegurança e ansiedade.

Alguns alunos, porém, relatam sentir-se tranquilos e à vontade, por que estudaram e já se acostumaram com as formas de avaliação (provas).

É evidente que a forma de avaliação determina a "ansiedade" do aluno, sendo que estes sempre indicam a "prova escrita individual" como o ponto crítico.

\section{OPINIÃO DOS ALUNOS QUANTO À AVALIAÇÃO NO CURSO DE PSICOLOGIA:}

Os alunos apontam para os objetivos do curso de psicologia, que enfatizam a preocupação com a formação crítica e transformadora dos educandos, mas, em contrapartida, na prática avaliativa, os conteúdos de reflexão são avaliados através da memorização. Assim, na opinião dos alunos, mantém-se certa incoerência entre a proposta de algumas disciplinas do curso e as formas de avaliação.

\section{COMENTÁRIOS, CRÍTICAS E SUGESTÕES:}

Dentro deste aspecto, a maior parte das respostas dos alunos foram com relação às críticas e comentários, porém fizeram também sugestões. Assim, com relação às críticas e comentários, as opiniões dos alunos se referiram de um lado, ao fato de que as avaliaçōes têm por objetivo a reprodução do conteúdo através da memorização. Entretanto, na opinião destes, as avaliações deveriam se pautar em torno de reflexões e visão crítica do assunto estudado. Por outro lado, criticaram também a relação professor-aluno, pois argumentam que em certas disciplinas há "falta de 
abertura para sugestões dos alunos", bem como "o professor deveria ter mais sensibilidade em relação às necessidades dos alunos".

As sugestões expressadas pelos alunos dizem respeito tanto à avaliação, quanto às formas de se trabalhar o processo ensino-aprendizagem.

\section{ANÁLISE CONCLUSIVA DOS DADOS:}

Frente à apresentação dos dados dos docentes e discentes do curso de Psicologia da UEL, quanto a "Avaliação Escolar", apresentamos algumas análises conclusivas e em seguida hipóteses de solução, ou seja, estratégias concernentes ao tema em questão, que possibilitem o encaminhamento do mesmo a soluções práticas.

Alguns aspectos relevantes serão aqui destacados com relação aos resultados obtidos no presente estudo:

- Através da investigação realizada junto aos professores, foi possivel verificar que estes, ao se referirem à avaliação educacional de forma mais ampla, se colocam diante de uma perspectiva transformadora. Entretanto, quando se referem à avaliação escolar (específica da disciplina), a maioria dos professores se colocam frente a uma perspectiva conservadora.

- Tanto professores quanto alunos referem-se à avaliação, na maioria das vezes, como "prova escrita individual".

A maioria dos professores entrevistados apontam também a prova escrita individual como a alternativa para a avaliação de conteúdos. As demais formas de avaliação são adotadas em função de se avaliar a postura ética e profissional do aluno.

Já os alunos, indicam a prova escrita em inúmeras ocasiões, sendo que quando o professor não a utiliza, alguns avaliados parecem não perceber que existe um sistema de avaliação para a disciplina.

Diante deste dado, cabe ressaltar que, a avaliação do tipo "classificatória", através de prova escrita individual, está impregnada no sistema educacional, tornando-se habitual tanto para professores, quanto para os alunos. Observa-se também que, mesmo quando seu emprego é questionado, não é visualizada outra forma de se avaliar o processo ensino-aprendizagem. Tal fato ocorre em função das exigências institucionais ou pelo próprio professor considerar que este tipo de avaliação (classificatória) é eficiente para a verificação da aprendizagem.

Assim, as outras formas de avaliação ficam relegadas a segundo plano e, às vezes, nem percebidas com tal objetivo. Estas não são questionadas e nem criticadas pelos alunos, pois muitas vezes nem as percebem como formas de avaliação propriamente dita.

- Como terceiro ponto para análise, destacamos que as considerações dos alunos acerca da avaliação se dirigiram em torno da "prova escrita individual", importando aqui, para eles, a forma de avaliação e não os objetivos e critérios de correção.

Os alunos identificam esta forma de avaliação como simples "reprodução de conteúdo" através de "memorização".

- Ainda, em relação à "prova escrita individual", os dados obtidos demonstram que a mesma pode ser utilizada para classificar o aluno, que segundo LUCKESI
(1986), através das notas e pontos a ele atribuídos tornase estigmatizado. Mas também destacamos para a complementação desta análise, que a mesma serve também para classificar o professor.

Neste sentido, a estruturação e organização do instrumento de avaliação (no caso, a "prova"), bem como os critérios de correção pertinentes, classificam o professor como "rígido", "exigente", "autoritário", "competente", ou então, como "relapso", "bonzinho", "incompetente", entre outros.

- No tocante à relação entre objetivos da disciplina e avaliações, vale ressaltar que embora para os professores esta relação esteja clara, o mesmo não ocorre para a metade dos alunos investigados.

Parece-nos que isto ocorre devido à forma de avaliação adotada (prova escrita individual) onde, com esta, as intenções do professor parecem não coincidir com as expectativas que os alunos têm da disciplina.

- Se as intenções do professor não coincidem com as expectativas do aluno, cabe destacar aqui que isto possivelmente esteja associado com:

a) à inadequação dos objetivos pretendidos com a avaliação e,

b) a forma de avaliação adotada ser considerada como reprodutora de uma realidade avaliativa tradicional.

- Quando nos referimos a uma prática educacional transformadora, nela está contida uma avaliação também transformadora. Entretanto, os dados demonstram que no presente estudo, a maior parte dos professores consideram este procedimento avaliativo adequado, mas alguns não o utilizam. Assim, revelam não saber como alterar sua prática educacional, pois a exigência institucional se faz em função de critérios classificatórios.

Consideramos portanto, que os professores fazem uso da avaliação classificatória e não da diagnóstica, embora reconheçam sua importância.

- Com relação ao curso de Psicologia como um todo, os alunos apontam para o fato de que o "sistema de avaliação tradicional", utilizado pela maioria dos professores, não condiz com os objetivos do curso e das disciplinas.

Nesta perspectiva, para um curso que tem como princípio fundamental o desenvolvimento de consciência crítica e a transformação social, existe um sistema de avaliação onde prevalece a memorização e reprodução de conteúdos.

Tal proposta de curso e disciplinas, comparada com o atual sistema de avaliação evidencia a incoerência existente entre o discurso teórico e a prática avaliativa.

- Podemos concluir que, de forma geral, as opiniōes dos professores entrevistados revelam três posicionamentos diferentes. De um lado, conservador, atribuindo a avaliação do tipo classificatória como único instrumento capaz de refletir o aprendizado. Nas colocações de LUCKESI (1986), na avaliação classificatória prevalece o julgamento do professor, sendo que cabe aqui, à avaliação, a função somente de classificar um objeto ou um ser humano histórico, em um padrão determinado.

Por outro lado, em uma postura transformadora, considera-se o aluno como agente ativo no processo ensino-aprendizagem, proporcionando-Ihe oportunidade para sugerir e opinar na organização da disciplina. Porém, o aluno nem sempre tem clareza de que com 
esta postura o professor propõe inovações no processo e acaba esperando que este o avalie pela forma tradicional.

Mediando as duas posturas mencionadas, o terceiro professor assim posicionou-se: se faz necessário refletir a prática pedagógica visando uma ação transformadora, considerando que a forma tradicional de avaliação não é adequada no processo ensinoaprendizagem. Entretanto, não realiza uma prática avaliativa transformadora dada às exigências institucionais que acabam requerendo do professor uma postura tradicional, mas busca formas de acompanhar o processo ensino-aprendizagem como um todo.

- Com relação às opiniões dos alunos, podemos concluir que estes, embora façam críticas quanto à forma tradicional de avaliação e revelem descontentamento, não se percebem como agentes deste processo. Se submetem às exigências do professor, mesmo estando descontentes com elas. Por outro lado, sugerem modificações, e dentre elas, uma se destaca: o próprio aluno gostaria de participar mais ativamente do processo de ensino-aprendizagem. O aluno acena essa possibilidade que poderá ser um passo para a transformação. Mas, o professor também terá que se apropriar desse desejo.

\section{HIPÓTESES DE SOLUÇÃO:}

A identificação de um "problema" levou-nos à sua investigação e posterior análise. Resta porém, apontar ainda estratégias que podem servir de suporte para desencadear a solução dos mesmos. São elas:

- divulgação do estudo, através de apresentações e publicações;

- apresentação do estudo ao Departamento, objeto da investigação e posteriormente aos outros dois departamentos do curso de Psicologia da UEL;

- propor ao Departamento um grupo de estudos sobre o tema "avaliação escolar";
- iniciar no Departamento e áreas de atuação, análises e reflexões sobre o tema;

- possibilitar debates sobre o tema, junto a alunos do curso de Psicologia.

\section{APLICAÇÃO NA REALIDADE:}

A oportunidade de desenvolver um trabalho específico sobre o tema "AVALIAÇÃO", possibilita eleger algumas alternativas que venham minimizar seus efeitos e inadequações no cotidiano escolar e na prática avaliativa do $3^{\circ}$ grau.

Com base nas hipóteses de solução apresentadas anteriormente, pretende-se desencadear análises $e$ reflexões acerca da avaliação escolar no curso de Psicologia da UEL.

Para tanto, as discussões dar-se-ão, primeiramente, em sub-grupos restritos às áreas de atuação (escolar, social e organizacional) do Departamento de Psicologia Social e Institucional.

Com o envolvimento das áreas de atuação acima mencionadas, será proposto ao Departamento um grupo de estudos sobre o tema "AVALIAÇÃO", que deve ser posteriormente ampliado para as constituição de um grupo de estudos que envolva os 3 Departamentos de Psicologia da UEL.

Através desse grupo de estudos, pretende-se ainda agilizar propostas que envolvam os alunos do curso de Psicologia em eventos, que possibilitem a ampliação do debate sobre a prática da avaliação escolar.

Paralelo ao desenvolvimento das estratégias explicitadas acima, objetiva-se também, ampliar a investigação sobre a avaliação escolar com consequente divulgação do trabalho, em termos de publicações e participação em eventos científicos.

Para finalizar, salienta-se que as propostas aplicáveis ao Curso de Psicologia poderão servir de incentivo para a ampliação dos debates nos demais cursos da UEL e para o ensino de $3^{\circ}$ grau em geral.

PALMIERI, M. W. A. R. School evaluation in the view of Psychology Students and teachears: the daily routine in the classroon. Semina: Ci. Soc./Hum., Londrina, v.16. n. 2., Ed. Especial, p. 20-26, out. 1995.

\begin{abstract}
The present study had as object checking the position of teachers and students around a polemic question - school evaluation - and verifying through the results from both groups the coerence between evaluation speech and avaliation praxis. Three teachers from Social and Institucional Psychology Departament and five students for each teacher investigated (15 students) were interviewed. The results were colected by instruments previoush elaborated. There were used structured with the leachers and questionnaires with the students. The results reveal different positions among teachers when talking about evaluation. Students criticize individual written tests because they demand the reproduction of the content given and memorization althoug they think it is the only way to evaluate the process of teaching and learning.
\end{abstract}

Key-words: school-evaluation, school instruments, school perfomance, teaching-learning process.

\title{
REFERÊNCIAS BIBLIOGRÁFICAS
}

CAMPANER, P. Isilda et al. Avaliação escolar: mera conseqüência da crise social ou instrumento para compreendê-la? In: Reunião Anual da ANPED, 16., 1993, Minas Gerais.

FERRETI, C.J. Equipe interdisciplinar, educação e ideologia. Educação e sociedade, n. 26, p.105-120, abr, 1987.
LUCKESI, C. Elementos para uma didática no contexto de uma pedagogia para a transformação. São Paulo: Loyola, 19b. p. 202-217. (Trabalho apresentado na III Conferência Brasileira de Educação - Simpósio).

LUCKESI, C. Avaliação educacional escolar: para além do autoritarismo. ANDE, São Paulo, v.5/6, n.10/11. p.45-51/47/49.

Semina: Ci. Soc./Hum. v.16., n. 2, Ed. Especial, p. 20-26. out. 1995 